\title{
Biosynthesis of Xanthan Gum by Xanthomonas campestris Using Cane Molasses as a Carbon Source
}

\author{
Bhumi Rajyaguru*, Ajit Varma*, Amit Kharkwal*† and Jasvir Singh** \\ *Department of Microbiology, Amity Institute of Microbial Technology, Amity University, Noida-201313, India \\ **Global Regulatory Affairs, Danisco (India) Private Limited, Gurgaon- 122002, India \\ $\nmid$ Corresponding author: Amit Kharkwal; ackharkwal@amity.edu
}

Nat. Env. \& Poll. Tech.

Website: www.neptjournal.com

Received: 16-04-2021

Revised: 15-05-2021

Accepted: 25-05-2021

Key Words:

Xanthomonas campestris

Cane molasses

Xanthan gum

Cauliflower leaf

\section{ABSTRACT}

The objective of the present study was to study the optimization conditions for the production of xanthan by Xanthomonas campestris from pre-treated sugarcane molasses. In the study, the optimization was carried out for different parameters including $\mathrm{pH}$, temperature, and incubation time for the pre-treated sugarcane molasses. The age of inoculums and time of culture growth $(6,12,18$ and $24 \mathrm{hrs})$, size of inoculums $(2 \%, 5 \%, 7.5 \%$ and $10 \%), \mathrm{pH}(6.6,6.8,7.0$ and 7.2$)$ and temperature $\left(25^{\circ} \mathrm{C}, 28^{\circ} \mathrm{C}, 30^{\circ} \mathrm{C}\right.$, $32^{\circ} \mathrm{C}$ and $37^{\circ} \mathrm{C}$ ) were studied. It was observed that the xanthan production was maximal with $7.5 \%$ $(\mathrm{v} / \mathrm{v})$ inoculums, pH. 7 at $30^{\circ} \mathrm{C}$ for $48 \mathrm{hrs}$. The study suggested that cane molasses is an appropriate agro-industrial substrate for xanthan gum fermentations, and further scale-up study is needed for gum production in the stirred fermenter.

\section{INTRODUCTION}

Polysaccharides are important natural products usually obtained through plant sources. The manufacture of polysaccharides by the fermentation process, instead of their extraction from plant sources, is a newly developed industry (Murugesan et al. 2012, Kleinitz et al. 1989). xanthan gum is one of the polysaccharides that can be produced by culturing microorganisms belonging to the Xanthomonas genus (Sutherland 1998, Becker et al.1998). The natural synthesis in bacteria is a dual-stage method wherein first stage growth of the microorganism is ideal and in second stage biosynthesis of the polysaccharide takes place with considerably no growth of the microorganism (Amanullah et al.1998). The polysaccharide or gums with novel properties are in high demand in food processing and many industrial operations. FDA allowed use of xanthan gum for general use in foods e.g., in cream cheese as a thickening and stabilizing agent (Chi-Liang et al.1996, FDA 2020).

Xanthan gum is also widely used in the oil industry, the pharmaceutical industry, and a variety of other industries. (Hassler 1990). However, commercially procured xanthan is relatively expensive. The higher cost is due to the costly substrate such as glucose or sucrose and high purity required for use in food products. For example, in the synthesis of food-grade xanthan, almost half of the cost is capitalized in its downstream processing. The cost of large-scale xanthan synthesis can be reduced by a significant amount if we use waste agricultural products as substrate (Frank \& Somkuti 1979, Jean-Claude et al. 1997).

One of the best available agricultural wastes is molasses. It is a by-product of sugar production, both from sugar beet as well as from sugarcane (Pinches \& Pallent 1986). Molasses is the surfeit syrup from the final stage of crystallization, from which further crystallization of sugar is profligate (Silva et al. 2009, Gumus et al. 2010). In contrast to sugar beet molasses, cane molasses differs in nitrogen levels. Also, cane molasses is a virtuous source of sucrose (almost 90\%) (Cadmus et al. 1978).

Using molasses as a substrate helps to reduce the cost of xanthan production and also help address bio-waste management issue and pollution (Honart et al. 1985). In the present study, we have attempted to produce xanthan gum using cane molasses bio-waste as a carbon source. Hence, we tried to optimize the growth conditions of Xanthomonas strains to maximize xanthan gum production.

\section{MATERIALS AND METHODS}

\section{Microorganism and Culture Conditions}

The Xanthomonas strains capable of producing xanthan gums were isolated from infected cauliflower leaves. The isolated strains were screened further for xanthan gum production 
and the isolate was identified based on cultural, morphological, Biochemical characteristics and molecular identification (accession number SUB9292907 16_rRNA_Xanthomonas MW741556. NCBI BLAST (http://www.ncbi.nlm.nih.gov/ Blast). A standard strain of Xanthomonas campestris (NCIM 5028) bacteria procured from NCIM-Pune was also used as a Reference Culture. The isolated $X$. campestris was grown in $50 \mathrm{~mL} \mathrm{LB}$ sucrose media (Sucrose: $1 \mathrm{~g} / \mathrm{L}$, Yeast Extract: $0.1 \mathrm{~g} / \mathrm{L}$, Peptone: $0.5 \mathrm{~g} / \mathrm{L}, \mathrm{NaCl}: 0.3 \mathrm{~g} / \mathrm{L}$ ) for $48 \mathrm{~h}$ at $34^{\circ} \mathrm{C}$. The isolated $X$. campestris strain was adapted to high molasses concentrations and maintained in submerged cultures on MGYP medium (Malt Extract: 0.3g, Glucose: 1g, Yeast Extract: 0.3g, Peptone: 0.5g, Water: 100mL, Agar: 2g, pH: 6.4-6.8).

\section{Collection and Analysis of Sugarcane Molasses}

The sugarcane molasses was purchased from a local source. The physico-chemical characteristics of sugar cane molasses such as color, odour, $\mathrm{pH}$, biochemical oxygen demand (BOD), chemical oxygen demand (COD), acidity, total Kjeldahl nitrogen, total suspended solids (TSS), oils and grease total dissolved solids (TDS) and sulphides were conducted using the standard method (APHA 2005).

\section{Pre-treatment of Sugarcane Molasses}

The cane molasses was pre-treated by the addition of $4 \mathrm{~g} / \mathrm{L}$ $\mathrm{K} 2 \mathrm{HPO} 4$ to the medium to obtain better xanthan gum yield and biomass production (Murugesan et al. 2012).

\section{Growth Adaptation of $X$. campestris in Molasses}

To achieve quick growth and thereupon higher productivity, the organism was adapted to high molasses environments by successive sub-culturing (4 passages). The pure culture obtained possessed improved characteristics in terms of growth and xanthan gum manufacture (Stavros et al. 2003).

\section{Culture Medium and Optimization}

The culture Medium used was $8 \%$ molasses pre-treated with $4 \mathrm{~g} / \mathrm{L} \mathrm{K}_{2} \mathrm{HPO}_{4}$. Growth parameters, viz. $\mathrm{pH}$, temperature, effect of inoculum, aeration, agitation and incubation period were standardized at bench scale for the Xanthomonas campestris strain (isolated from cauliflower leaves) to get maximum gum production. Various parameters such as age of inoculums time of culture growth $(6,12,18,24 \mathrm{hrs})$, size of inoculums $(2 \%, 5 \%, 7.5 \%, 10 \%), \mathrm{pH}(6.6,6.8,7.0,7.2)$ and temperature $\left(25^{\circ} \mathrm{C}, 28^{\circ} \mathrm{C}, 30^{\circ} \mathrm{C}, 32^{\circ} \mathrm{C}, 37^{\circ} \mathrm{C}\right)$ and the incubation period $(12,24,48,72 \mathrm{hrs})$ were observed and optimized for best growth. Other factors such as aeration and agitation of culture flasks were also optimized. It was pragmatic that shaker flasks provided better aeration to the culture and agitation is required for better mass transfer.

\section{Assay of Xanthan Gum}

The final product in form of xanthan Gum was obtained in the optimized culture of Xanthomonas campestris. The presence of xanthan gum was determined by test method as per Indian Pharmacopoeia, 1996. Briefly, the solution was lysed with $0.1 \mathrm{M}$ hydrochloric acid, the supernatant was treated with dinitrophenyl hydrazine- hydrochloric solution followed by methyl acetate and then sodium carbonate. An absorption maximum was measured at $375 \mathrm{~nm}$ using sodium carbonate as the compensation liquid.

\section{Xanthan Gum Recovery}

Precipitation of xanthan gum was done with isopropanol ( $2 \mathrm{x}$ volume of supernatant) to which $1 \%(\mathrm{w} / \mathrm{v})$ of potassium chloride was added. The dried biomass and xanthan gum produced were determined by drying in an oven at $105^{\circ} \mathrm{C}$ and $40^{\circ} \mathrm{C}$, respectively and measured using Brookfield Viscometer (LABPRO, Model No. LMDV-60) at $25^{\circ} \mathrm{C}$ (Carignatto et al. 2011).

\section{RESULTS AND DISCUSSION}

The "xanthan gum" is produced in dual stages by Xanthomonas campestris. The bacterium is cultivated in Nutrient Agar and the biomass formed is used as inoculum for the subsequent stage in which the gum is formed by batch process. The biomass and xanthan gum formed were determined by drying in an oven at $105^{\circ} \mathrm{C}$ and $40^{\circ} \mathrm{C}$. Xanthomonas strains capable of producing gums were isolated from infected plants (Brassica oleracea var. botrytis). Morphological and biochemical characterization of Xanthomonas campestris was done (Fig. 1).

To obtain a good yield of xanthan gum, various parameters such as carbon source, $\mathrm{pH}$, temperature and incubation time were optimized. It was established that xanthan gum was attained in the best quantity at $30^{\circ} \mathrm{C}$ temperature (Fig. 2). The cell dissociation enhanced metabolite production giving high continuous yield (Psomas et al. 2007, Esgalhado et al. 1995, Garcia-Ochoa et al. 1996). A comparable observation has been made in other optimization studies wherein xanthan production was increased with a change in physical parameters (Kerdsup et al. 2011, Borges et al. 2008, Kalogiannis et al. 2003). Amongst other growth parameters, it was found that xanthan production was maximal with $7.5 \%(\mathrm{v} / \mathrm{v})$ inoculums, pH.7 at $30^{\circ} \mathrm{C}$ at $48 \mathrm{hrs}$. (Figs. 3 and 4 ).

The parameters were standardized at bench scale for the effect of inoculums and age of Inoculums at different incubation time points including 6, 12, 18, 24 and $48 \mathrm{hrs}$. culture respectively. It was found that $48 \mathrm{hrs}$. were optimal for a good yield of xanthan gum. Also, the ideal size of inoculums 

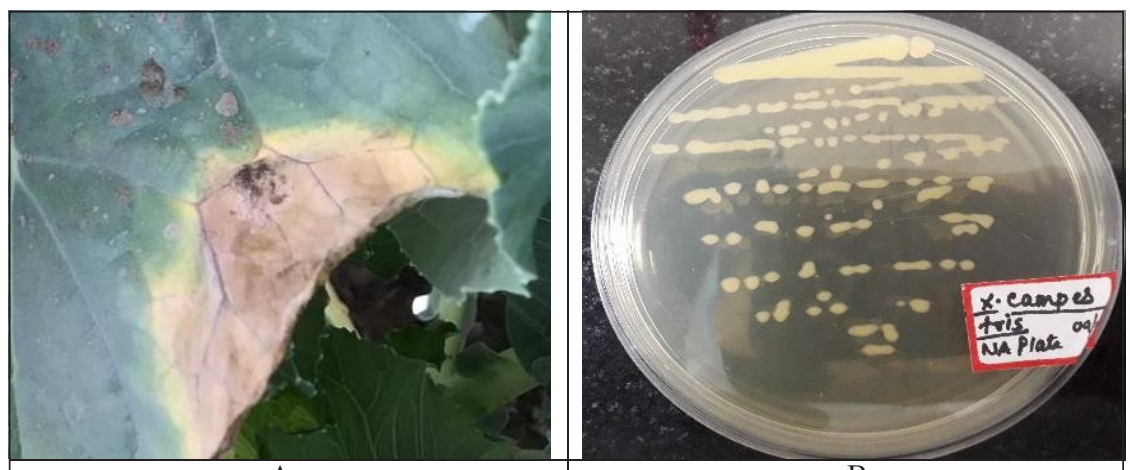

A

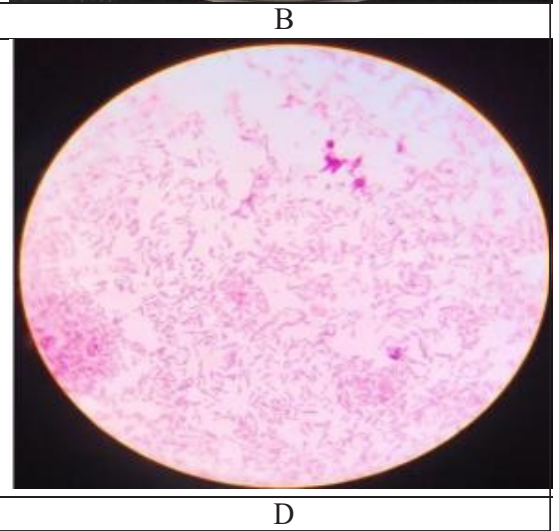

Fig. 1: A-infected Cauliflower leaf with Xanthomonas, B and C- isolated Xanthomonas strains, capable of producing gums, from infected plants (Cauliflower), D-The bacterial genus Xanthomonas are small, motile, Gram-negative rods, aerobic, and produce Cremish/yellow pigments and characteristically parasitize plants.

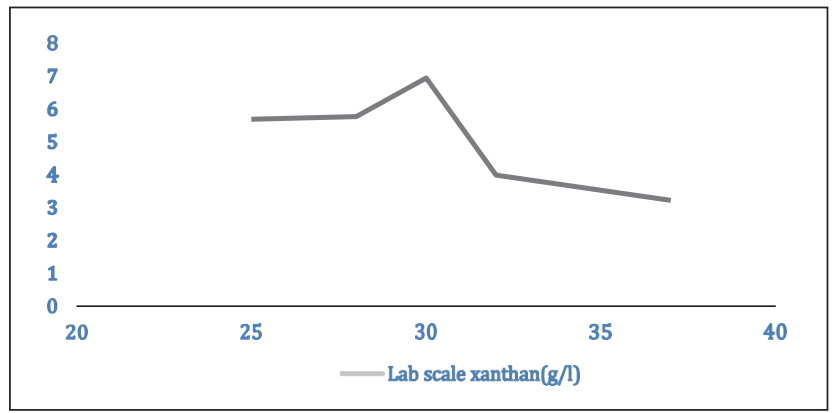

Fig. 2: Temperature variation of different quantity of xanthan production.

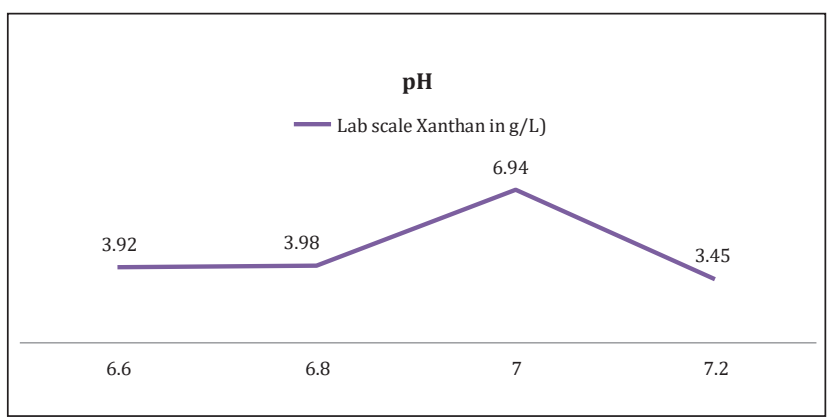

Fig. 3: Production of xanthan at different $\mathrm{pH}$.

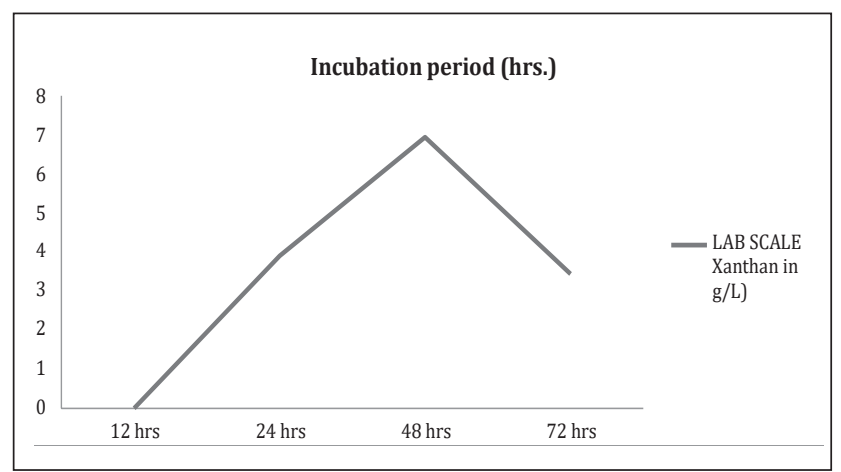

Fig. 4: Production of xanthan at different incubation time points.

was tested to find the appropriate amount. It was observed that $12 \mathrm{hrs}$ of culture as ideal age of inoculum and size of inoculums $7.5 \%$ of were best for gum yield as mentioned in Table 1. Aeration plays a vital role in determining the yield of any product in closed culture. It was observed that shaker flasks provide the right amount of aeration to X. campestris culture. Agitation of culture flasks is also required for better mass transfer.

This study looked into the possibility of making xanthan gum from cane molasses $(8 \%$ molasses pre-treated with 4 
Table 1: Effect of ioculum.

\begin{tabular}{|ll|}
\hline \multicolumn{2}{|c|}{ Age of inoculum, 12 hrs culture is optimum } \\
\hline Age of inoculum & Lab Scale (Xanthan gum g/L) \\
\hline $6 \mathrm{hrs}$ & ND \\
$12 \mathrm{hrs}$ & 6.94 \\
$18 \mathrm{hrs}$ & 4.32 \\
$24 \mathrm{hrs}$ & 2.34 \\
\hline
\end{tabular}

\begin{tabular}{|ll|}
\hline \multicolumn{2}{|c|}{ Size of inoculum: $7.5 \%$ is optimum } \\
\hline Size of Inoculum & Lab Scale (Xanthan gum g/L) \\
\hline 2 & 3.72 \\
5 & 3.96 \\
7.5 & 6.94 \\
10 & 2.1 \\
\hline
\end{tabular}

$\mathrm{g} / \mathrm{L} \mathrm{K}_{2} \mathrm{HPO}_{4}$ ). In most cases, using low-cost substrates can help biological processes run more efficiently (Yoo \& Harcum 1999, Stredansky \& Conti 1999, Psomas et al. 2007). Glucose syrup is currently produced primarily from starchy materials. Because of the cost and availability of starch, the use of glucose syrup as a substitute for pure glucose is favored in a variety of industries, including the beverage and ethanol industries. (Kobayashi \& Nakamura 2004). Cane molasses was used as a carbon source for the production of xanthan gum in this study. Indeed, this work is a first step toward increasing the efficiency of the xanthan gum manufacturing process.

The purity of xanthan gum is generally an important consideration, particularly when the product is intended for use in the food industry. The use of cane molasses in this study could help to reduce the presence of unwanted substrate ingredients in the final product (García et al. 2000, Funahashi et al.1987). Xanthomonas campestris grew well on LB sucrose media and was maintained on MGYP medium and cane molasses was pre-treated by addition of K2HPO4 to the medium to obtain better xanthan gum yield and biomass production. The strain

Xanthomonas campestris performed better in xanthan production because it had a higher maximum growth rate.

Few reports are showing different culture conditions for xanthan production using Xanthomonas campestris (Shu $\&$ Yang 1990). The conditions and parameters vary in each indicating that there is always a good scope of experimenting with the best conditions producing xanthan gum. This might be due to varied carbon sources and slight differences in the culture of Xanthomonas campestris used for inoculation.

\section{CONCLUSION}

In the current study, the Xanthomonas strains capable of producing gums from infected cauliflower were isolated and screened further for xanthan gum production. The potent isolated strain was used for gum production using cane molasses as a carbon source. The study concluded that xanthan production was maximum with $7.5 \%(\mathrm{v} / \mathrm{v})$ inoculum, 12 hrs culture, pH. 7 at $30^{\circ} \mathrm{C}$ for $48 \mathrm{hrs}$ with the isolated strain. Further, scale-up studies of gum production in the stirred fermenter (10 L) are underway.

\section{ACKNOWLEDGEMENTS}

The authors are highly grateful to the Faculty of Microbiology, Amity Institute of Microbial Technology, Amity University, Noida for their support and guidance, special thanks to Dr. Rahul Singh and Ms. Madhulika Ganguly from Emami Ltd. for their support and Dr. Meghna Singh for her immense help and support.

\section{REFERENCES}

Amanullah, A., Satti, S. and Nienow, A.W. 1998. Enhancing xanthan fermentation by different modes of feeding. Biotechnology Progress, 14: 265-269.

APHA 2005. Standard Methods for the Examinations of Water and Wastewater, 21th edition. American Public Health Association, Washington D.C.

Becker, A., Katzen, F., Puhler, A. and Ielpi, L. 1998. Xanthan gum biosynthesis and application: A biochemical/genetic perspective. Applied Microbiology Biotechnology, 50: 145-152.

Borges, C.D., da Moreira, A.S., Vendruscolo, C.T. and Ayub, M.A.Z. 2008. Influence of agitation and aeration in xanthan production by Xanthomonas campestris pv pruni strain 101. Revista Argentina de Microbiologia, 40: 81-85.

Cadmus, M.C., Knutson, C.A., Lagoda, A.A., Pittsley, J.E. and Burton, K.A. 1978. Synthetic media for production of quality xanthan gum in 20 liter fermentors. Biotechnol Bioeng., 20: 1003- 1014.

Carignatto, Cíntia, Oliveira, Kassandra Sussi, Lima, Valéria and de Oliva Neto, Pedro 2011. New culture medium to xanthan production by Xanthomonas campestris pv. campestris. Indian Journal of Microbiology, 51: 283-288.

Chi-Liang, W., Ka, T.C., Nien-Tsung, L. and Yi-Hsiung, T. 1996. Increase of xanthan production by self-cloning of a 3.0-kb EcoRI-KpnI chromosomal fragment in Xanthomonas campestris. Biotechnology Letter, 18: $1301-1304$

Esgalhado, M.E., Roseiro, J.C. and Amaral, C.M.T. 1995. Interactive effects of $\mathrm{pH}$ and temperature on cell growth and polymer production by Xanthomonas campestris. Process Biochemistry, 30: 667-671.

FDA 2020. Code of Federal Regulations, Food and Drugs, Chapter I--Food and Drug Administration, Food Additives Permitted for Direct Addition to Food For Human Consumption (https://www.accessdata.fda.gov/scripts/ $\mathrm{cdrh} / \mathrm{cfdocs} / \mathrm{cfcfr} / \mathrm{cfrsearch} . \mathrm{cfm}$ ?fr=172.695).

Frank, J.F. and Somkuti, G.A. 1979. General properties of beta-galactosidase of Xanthomonas campestris. Appl. Environ. Microbiol., 38: 554-556.

Funahashi, H., Yoshida, T. and Taguchi, H. 1987. Effect of glucose concentration on xanthan gum production by Xanthomonas campestris. J. Ferment. Technol., 65: 603-606.

García, O.F., Castro, E.G. and Santos, V.E. 2000. Oxygen transfer and uptake rates during xanthan gum production. Enzyme Microb. Technol., 27: 680-90.

Garcia-Ochoa, F., Santos, V.E. and Alcon, A. 1996. Simulation of xanthan gum 
production by a chemically structured kinetic model. Mathematics and Computers in Simulation, 42: 187-195.

Gumus, T., Demirci, A.S., Mirik, M., Arici, M. and Aysan, Y. 2010. Xanthan gum production of Xanthomonas spp. isolated from different plants. Food Sci. Biotechnol., 19: 201-206.

Hassler, R.A. 1990. Genetic engineering of polysaccharide structure: Production of variants of xanthan gum in Xanthomonas campestris. Biotechnology Progress, 6: 182-187.

Honart, P., Paquot, M., Hermans, L., Alaoui, H. and d'Ippolito, P. 1985. Xanthan production by Xanthomonas campestris NRRL B-1459 and interfacial approach by zeta potential measurement. Enzyme and Microbial Technology, 7: 235-238.

Indian Pharmacopoeia 1996. Vol. 1. New Delhi: Controller of Publication, Government of India, Ministry of Health and Family Welfare, 736.

Jean-Claude, M.G.T., Roland, H.F.B. and Benedicte, L.T.W. 1997. Production of xanthan gum by fermenting a feedstock containing a mixture of mannose and glucose. Biotechnol. Adv., 15: 267.

Kalogiannis, S., Iakovidou, G., Liakopoulou-Kyriakides, M., Kyriakidis, D. and Skaracis, G. 2003. Optimization of xanthan gum production by Xanthomonas campestris grown in molasses. Process Biochem., 39: 249-256.

Kerdsup, P., Tantratian, S., Sanguandeekul, R. and Imjongjirak, C. 2011. Xanthan production by mutant strain of Xanthomonas campestris TISTR 840 in raw cassava starch medium. Food and Bioprocess Technology, 4: 1459-1462.

Kleinitz, W., Littman, M. and Herbst, H. 1989. Screening of xanthan biopolymer for a high salinity oil reservoir, Proc. Fifth European Symposium on improved oil recovery, Budapest, pp. 25-27.

Kobayashi, F. and Nakamura, Y. 2004. Mathematical model of direct ethanol production from starch in immobilized recombinant yeast culture. Biochem. Eng. J., 21: 93-101.

Murugesan, A.G., Dhevahi, B., Gowdhaman, D., Bala Amutha, K. and Sathesh Prabu, C. 2012. Production of xanthan employing Xanthomonas campestris using sugarcane molasses. American Journal of Environmental Engineering, 2(2): 31-34.

Murugesan, A.G., Dhevahi, B., Gowdhaman, D., Bala Amutha, K. and Sathesh Prabu, C. 2012. Production of xanthan employing Xanthomonas campestris using sugarcane molasses. American Journal of Environmental Engineering, 2(2): 31-34.

Pinches, A. and Pallent, L.J. 1986. Rate and yield relationships in the production of xanthan gum by batch fermentations using complex and chemically defined growth media. Biotechnol. Bioeng., 28: 1484-1496.

Psomas, S.K., Kyriakides, M.L. and Kyriakidis, D.A. 2007. Optimization study of xanthan gum production using response surface methodology. Biochem. Eng. J., 35: 273-80.

Psomas, S.K., Liakopoulou-Kyriakides, M. and Kyriakidis, D.A. 2007. Optimization study of xanthan gum production using response surface methodology. Biochemical Engineering Journal, 35: 273-280.

Shu, C.H. and Yang, S.T. 1990. Effect of temperature on cell growth and xanthan production in batch culture of Xanthomonas campestris. Biotechnol. Bioeng., 35: 454-468.

Silva, M.F., Fornari, R.C.G., Mazutti, M.A., Oliveira, D., Padilha, F.F. and Cichoski, A.J. 2009. Production and characterization of xanthan gum by Xanthomonas campestris using cheese whey as sole carbon source. Journal of Food Engineering, 90: 119-123.

Stavros, K., Gesthimani, I., Maria, L.K., Dimitrios, A. K. and George, N. S. 2003. Optimization of xanthan gum production by Xanthomonas campestris grown in molasses. Process Biochemistry, 39: 249-256.

Stredansky, M. and Conti, E. 1999. Xanthan production by solid-state fermentation. Process Biochem., 34: 581-587.

Sutherland, I.W. 1998. Novel and established applications of microbial polysaccharides.

Trends in Biotechnology, 16: 41-46.

Yoo, S.D. and Harcum, S.W. 1999. Xanthan gum production from waste sugar beet pulp. Bioresour. Technol., 70: 105-109. 